\title{
Ionic conductivity and diffusion coefficient of barium-chloride-based polymer electrolyte with poly(vinyl alcohol)-poly(4-styrenesulphonic acid) polymer complex
}

\author{
MAYANK PANDEY ${ }^{1}$, GIRISH M JOSHI ${ }^{1, *}$ and NARENDRA NATH GHOSH ${ }^{2}$ \\ ${ }^{1}$ Polymer Nanocomposite Laboratory, Center for Crystal Growth, Department of Physics, School of Advanced Sciences, \\ VIT University, Vellore 632014, India \\ ${ }^{2}$ Department of Chemistry, Birla Institute of Technology and Science, Pilani, K K Birla Goa Campus, Goa 403726, India \\ *Author for correspondence (varadgm@gmail.com)
}

MS received 23 February 2016; accepted 2 November 2016; published online 26 July 2017

\begin{abstract}
A composite polymer electrolyte comprising poly(vinyl alcohol)-poly(4-styrenesulphonic acid) with barium chloride dihydrate $\left(\mathrm{BaCl}_{2} \cdot 2 \mathrm{H}_{2} \mathrm{O}\right)$ salt complex has been synthesized following the usual solution casting. The ionic conductivity of polymer electrolyte was analysed by impedance spectroscopy. The highest room temperature (at $30^{\circ} \mathrm{C}$ ) conductivity evaluated was $9.38 \times 10^{-6} \mathrm{~S} \mathrm{~cm}^{-1}$ for $20 \mathrm{wt} \%$ loading of $\mathrm{BaCl}_{2}$ in the polymer electrolyte. This has been referred to as the optimum conducting composition. The temperature-dependent ionic conductivity of the polymer electrolyte exhibits the Arrhenius relationship, which represents the hopping of ions in polymer composites. Cation and anion diffusion coefficients are evaluated using the Trukhan model. The transference number and enhanced conductivity imply that the charge transportation is due to ions. Therefore this polymer electrolyte can be further studied for the development of electrochemical device applications.
\end{abstract}

Keywords. Polymer electrolytes; impedance spectroscopy; diffusion coefficient; ionic conductivity.

\section{Introduction}

The development of polymer electrolytes is a highly specialized interdisciplinary field, which covers the fields of electrochemistry, polymer science, organic and inorganic chemistry. The properties of polymer electrolytes such as their high compliance, good adherence to electrodes and the possibility of fabricating the polymers into thin films make them suitable for device fabrication $[1,2]$. The growing demand of industries toward the fabrication of composite polymer electrolytes is to obtain small, light-weight and high-energy-density rechargeable power sources and also for the development of fuel cells, solar cells, supercapacitors, etc. Composite polymer electrolytes are also important in terms of shape, geometry and a capability for strong electrode-electrolyte contacts [3]. A recent challenge in polymer electrolyte discipline is to find low-cost membranes with good ionic conductivity. The incorporation of an inert filler into host polymer system has greatly enhanced the amorphous region of electrolytes, which helps in easy ionic movement [4,5].

Poly(4-styrenesulphonic acid) (PSSA), a polymer derived from polystyrene with sulphonic acid as a functional group, has been chosen as the host polymer in the present study. The PSSA polymer contains a strong acid $\left(\mathrm{SO}_{3}^{-}\right)[6,7]$. Poly(vinyl alcohol) (PVA) is used in the present study due to its chemical stability, easy processibility to films and its charge-storage capability [8,9]. PVA is thermally stable over a large temperature range of 173-473 K. Organic or inorganic compounds are used to improve the properties of polymer electrolytes. The present polymer electrolyte has been prepared by adding barium chloride dihydrate $\left(\mathrm{BaCl}_{2} \cdot 2 \mathrm{H}_{2} \mathrm{O}\right)$, an inorganic compound, into the PVA-PSSA polymer system. The motivation to incorporate an inorganic compound into polymer matrix is to increase its ionic conductivity and electrical performance [10]. There are several polymer electrolytes already reported using various ionic additives such as $\mathrm{SiO}_{2}$ [11], Li-ion [12], $\mathrm{CeO}_{2}$ [13], $\mathrm{LiFePO}_{4}$ [14] and $\mathrm{ZrO}_{2}-\mathrm{NC}$ [15]. Barium chloride dihydrate is a white crystalline powder containing two molecules of water, which makes it an important water-soluble barium salt. The main objective of the present research is to reveal the effect of $\mathrm{BaCl}_{2}$ on the ionic conductivity properties of PSSA-PVA polymer electrolyte.

In the present work, structural, thermal and ionic properties of the synthesized composites were characterized. Temperature-dependent ionic conductivity for different loadings (wt\%) of $\mathrm{BaCl}_{2}$ was investigated to identify the optimum conducting composition of PSSA-PVA- $\mathrm{BaCl}_{2}$ polymer electrolyte material. Higher loading (wt $\%$ ) of $\mathrm{BaCl}_{2}$ ensures better cross-linking with the polymer system. Hence, $\mathrm{BaCl}_{2}$ plays a vital role as a cross-linking agent with the PSSAPVA polymer system. Moreover, the presence of $\mathrm{BaCl}_{2} \cdot 2 \mathrm{H}_{2} \mathrm{O}$ 
increases inter/intra-hydrogen bonding, which is reflected in absorption spectra. Therefore $\mathrm{BaCl}_{2} \cdot 2 \mathrm{H}_{2} \mathrm{O}$ is a good selection for developing a polymer electrolyte as well as for good ionic conductivity results. In the present study we have also focused on the diffusion coefficient and ionic concentration of free charge carriers.

\section{Experimental}

\subsection{Materials}

The host polymer PSSA of MW 75,000, product number 561223, was procured from Sigma Aldrich, Germany. White granules PVA of MW 125,000 LR grade was obtained from SD Fine Chem. Limited, Mumbai, India. The inorganic compound barium chloride dihydrate $\left(\mathrm{BaCl}_{2} \cdot 2 \mathrm{H}_{2} \mathrm{O}\right)$ of $\mathrm{MW}$ 244.28, Batch T/832417, was obtained from Sisco Research Laboratory, Mumbai, India.

\subsection{Synthesis of $\mathrm{BaCl}_{2}$-based PSSA-PVA polymer electrolyte}

The samples were prepared by dissolving appropriate wt $\%$ of PSSA-PVA polymers in distilled water. The solution was stirred $(350 \mathrm{rpm})$ at room temperature $\left(30^{\circ} \mathrm{C}\right)$ for $4 \mathrm{~h}$ until the mixture appeared like a homogeneous liquid. Then, $\mathrm{BaCl}_{2} \cdot 2 \mathrm{H}_{2} \mathrm{O}(5,10,15$ and $20 \mathrm{wt} \%)$ was dissolved in distilled water and sonicated (for $10 \mathrm{~min}$ ) to achieve proper dispersion. Later on, the sonicated solution of barium chloride was mixed with PSSA-PVA polymer solution and stirred $(350 \mathrm{rpm})$ at room temperature $\left(30^{\circ} \mathrm{C}\right)$ for $4 \mathrm{~h}$. The prepared homogeneous solution was poured into a Petri dish and kept for drying for $12 \mathrm{~h}$ (at $60^{\circ} \mathrm{C}$ in an oven). The prepared films were kept in desiccators until no water was left in the film. The proposed scheme of polymer composite electrolyte is shown in figure 1. It shows the good cross-linking of $\mathrm{BaCl}_{2}$ with polymer system and also indicates that the presence of $\mathrm{BaCl}_{2} \cdot 2 \mathrm{H}_{2} \mathrm{O}$ increases inter/intra-hydrogen bonding, which is reflected in absorption spectra. Polymer composite films of thickness $50 \mu \mathrm{m}$ was obtained by this procedure and used for further characterization.

\subsection{Characterization methods}

The structural characterization of $\mathrm{BaCl}_{2}$-doped polymer electrolytes was performed by the X-ray diffraction (XRD) technique. Composites were analysed using $\mathrm{Cu} \mathrm{K}_{\alpha}$ radiation of wavelength $\lambda=1.5406 \AA$ produced by a Bruker AXS D8 focus advance $\mathrm{X}$-ray diffractometer (Rigaku, Japan, Tokyo) with a 'Ni-filter'. The scans were taken in the $2 \theta$ range from 10 to $80^{\circ}$ with a scanning speed and step size of $1^{\circ} \mathrm{min}^{-1}$ and $0.01^{\circ}$, respectively. The complex chemical composition and functional group study of present polymer electrolyte were recorded using Fourier transform infrared (FTIR) spectroscopy (make Shimadzu-IR Affinity-1 spectrometer) in the wavenumber range of $500-4000 \mathrm{~cm}^{-1}$ operated in a transmittance mode. UV-visible spectroscopy was carried out using a Shimazdu UV-2401PC UV-visible spectrophotometer in the range of $200-600 \mathrm{~nm}$. The optical absorbance of prepared polymer electrolyte was recorded and energy band gap was evaluated from the UV spectrum. The micro-structural properties and optical images of polymer electrolytes at $500 \mu \mathrm{m}$ were obtained by Olympus BX61 optical microscopy. Differential scanning calorimetry (DSC) experiments were performed using a DSC-60, Shimadju, Japan, for thermal characterization of the polymer composite. The sample for DSC analysis was cut into small pieces of $2.5 \mathrm{mg}$ weight from the original films. All the experiments were carried

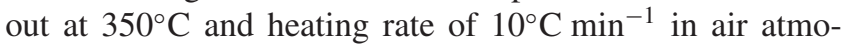
sphere.

The electrical properties of PSSA-PVA- $\mathrm{BaCl}_{2}$ composite polymer electrolytes were demonstrated by ac-impedance spectroscopy and ionic conductivity parameters. The sample (size $10 \mathrm{~mm}$ diameter, silver pasted both sides) was placed in fixture assembly and kept inside a dry temperature calibrator. A PSM-1735 impedance analyzer was used over varying ranges of temperature $\left(40-150^{\circ} \mathrm{C}\right)$ and broadband frequency $(50 \mathrm{~Hz}-1 \mathrm{MHz})$. For accurate results all the samples were measured three times; their averages were drawn and analysed.

\section{Result and discussion}

\subsection{XRD analysis}

The XRD analysis is useful to determine the structural and crystallization properties of polymer electrolytes. In order to investigate the effect of inorganic salt $\left(\mathrm{BaCl}_{2} \cdot 2 \mathrm{H}_{2} \mathrm{O}\right)$ at different loadings (wt $\%$ ) on the structure of PSSA-PVA polymer system, XRD analysis has been performed. Figure 2(i, ii) presents the XRD spectra of pure and doped polymer electrolytes. The XRD pattern of pure PSSA, PVA and $\mathrm{BaCl}_{2} \cdot 2 \mathrm{H}_{2} \mathrm{O}$ is shown in figure 2(i). The presence of broad humps confirms the completely amorphous nature of pure PSSA polymer and peaks for PVA reveals its semicrystalline nature. The sharp peaks shown in figure 2(i) reveal the highly crystalline nature of $\mathrm{BaCl}_{2}$. The XRD spectra of polymer electrolyte with different loadings (wt\%) of $\mathrm{BaCl}_{2}$ are shown in figure 2(ii) (a-d). The decreases in relative intensity of apparent peaks are directly proportional to loading (wt \%) of the salt. The results can be interpreted by considering Hodge et al [16], which established a correlation between the height of the peaks and the degree of crystallinity. The major changes in XRD peaks have been observed at $2 \theta=19-20^{\circ}$ for the complex polymer system. The XRD spectra present more crystalline peaks for $10 \mathrm{wt} \%$ loading of $\mathrm{BaCl}_{2}$ in the polymer electrolyte. This is due to proper incorporation of $\mathrm{BaCl}_{2}$ in the polymer electrolyte system. The evaluated values of interplanar spacing $(d)$ and average crystallite size 


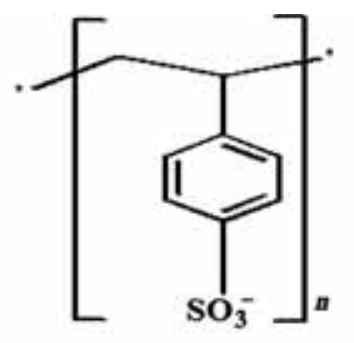

PSSA
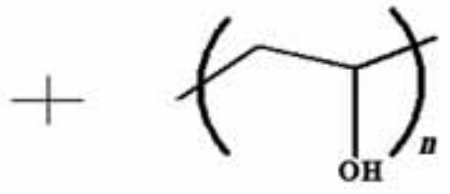

PVA

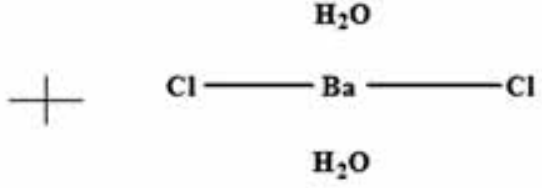

$\mathrm{BaCl}_{2} \cdot 2 \mathrm{H}_{2} \mathrm{O}$

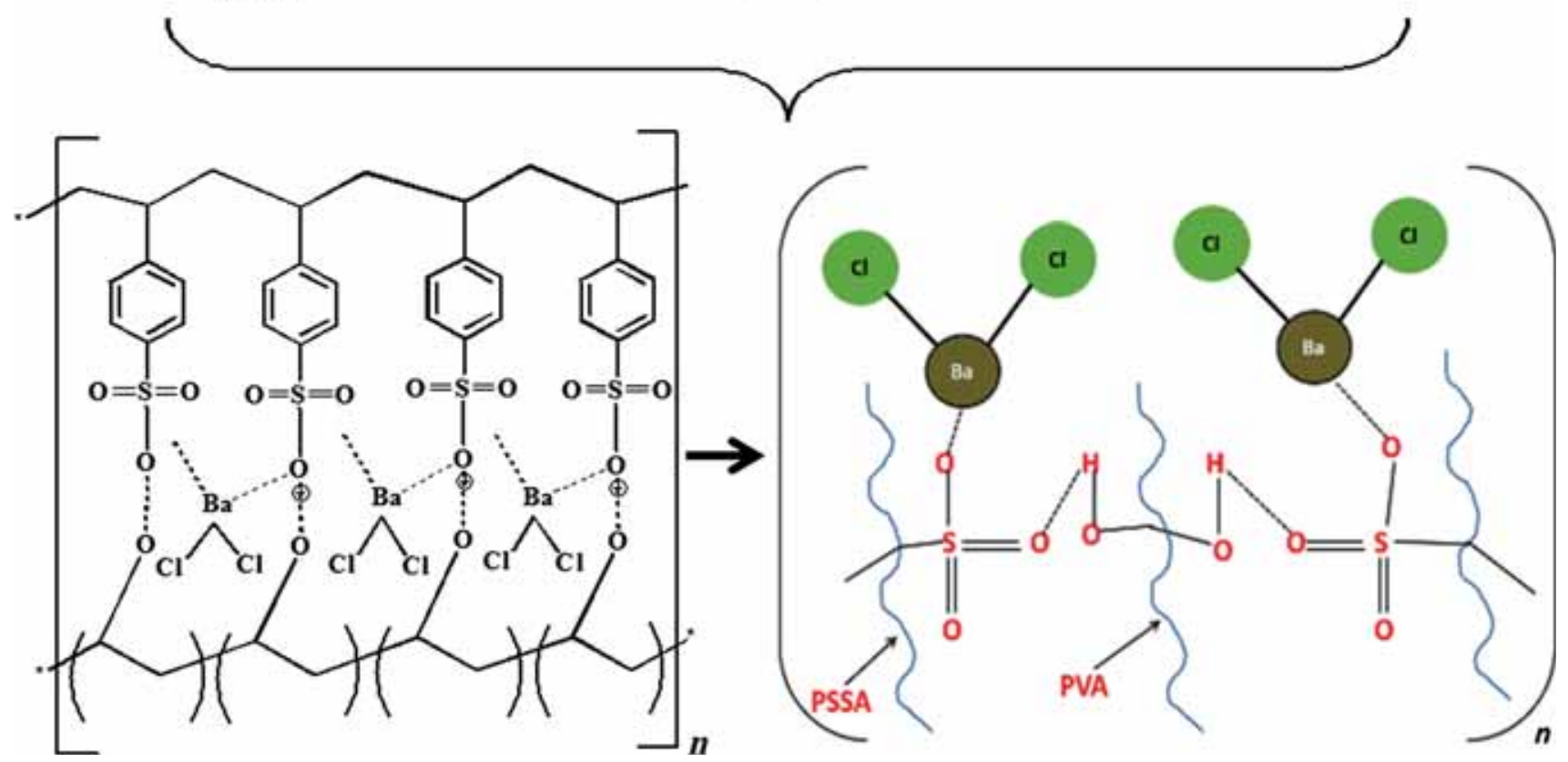

Figure 1. Schematic illustration of cross-linked $\mathrm{BaCl}_{2}$ incorporated polymer electrolytes.

(D) for pure and doped polymer systems are tabulated in table 1 .

The average crystallite size $(D)$ of the samples was estimated using Scherer's formula:

$$
D=\frac{0.9 \lambda}{\beta \cos \theta},
$$

where $\lambda$ is the $\mathrm{X}$-ray wavelength of $\mathrm{Cu}-\mathrm{K} \alpha$ radiation source $(1.54 \AA), \beta$ is the full-width at half-maximum (FWHM) intensity of the diffraction peak and $\theta$ is the Bragg angle.

It can be noticed that the interplanar spacing $(d)$ decreases and crystallinity increases with the loading of $\mathrm{BaCl}_{2}$ as seen in table 1 . Most of the polymer systems have a substantial volume fraction of amorphous phase. However, in the present work, after adding $\mathrm{BaCl}_{2}$ in the PVA-PSSA polymer composite, many crystalline peaks appeared. The highest degree of crystallinity for $10 \mathrm{wt} \%$ loading of $\mathrm{BaCl}_{2}$ may be due to complete dissociation of salt in the polymer system. This result probably shows the proper growth of salt in PSSA-PVA polymer complex. The decrease in crystallinity supports better alignment of polymer chain as well as good conductivity [17].

\subsection{FTIR analysis}

FTIR has been used to characterize the chain structure and to determine the change in functional group on addition of salt into the polymer system. The interaction between salt and host polymer influences the basic structure of polymer backbone and active infrared modes of vibration will be affected [18]. The wavenumber of the FTIR spectrum is related to the chemical structure of composites. Therefore a change in FTIR spectrum is obtained due to interaction of atoms and ions in the polymer electrolyte [19]. The FTIR spectra of PSSA-PVA- $\mathrm{BaCl}_{2} \cdot 2 \mathrm{H}_{2} \mathrm{O}$ polymer electrolyte complexes are shown in figure 3. The FTIR band for PVA as shown in figure 3(i) represents the intermolecular $-\mathrm{OH}$ bending at $3348 \mathrm{~cm}^{-1}, \mathrm{C}-\mathrm{H}$ stretching at $2928 \mathrm{~cm}^{-1}, \mathrm{C}=\mathrm{O}$ stretching at $1733 \mathrm{~cm}^{-1}$ and $-\mathrm{OH}$ bending (absorbed water) at $1640 \mathrm{~cm}^{-1}$. The peaks at 1438 and $1378 \mathrm{~cm}^{-1}$ correspond to wagging of $\mathrm{CH}_{2}$ vibration and the peak at $1247 \mathrm{~cm}^{-1}$ corresponds to $\mathrm{C}-\mathrm{H}$ wagging. The bands for $\mathrm{C}-\mathrm{O}$ stretching and $\mathrm{O}-\mathrm{H}$ stretching are observed, respectively, at 1096 and $1089 \mathrm{~cm}^{-1}$. The bands at 916 and $850 \mathrm{~cm}^{-1}$ represent the skeletal vibration. 

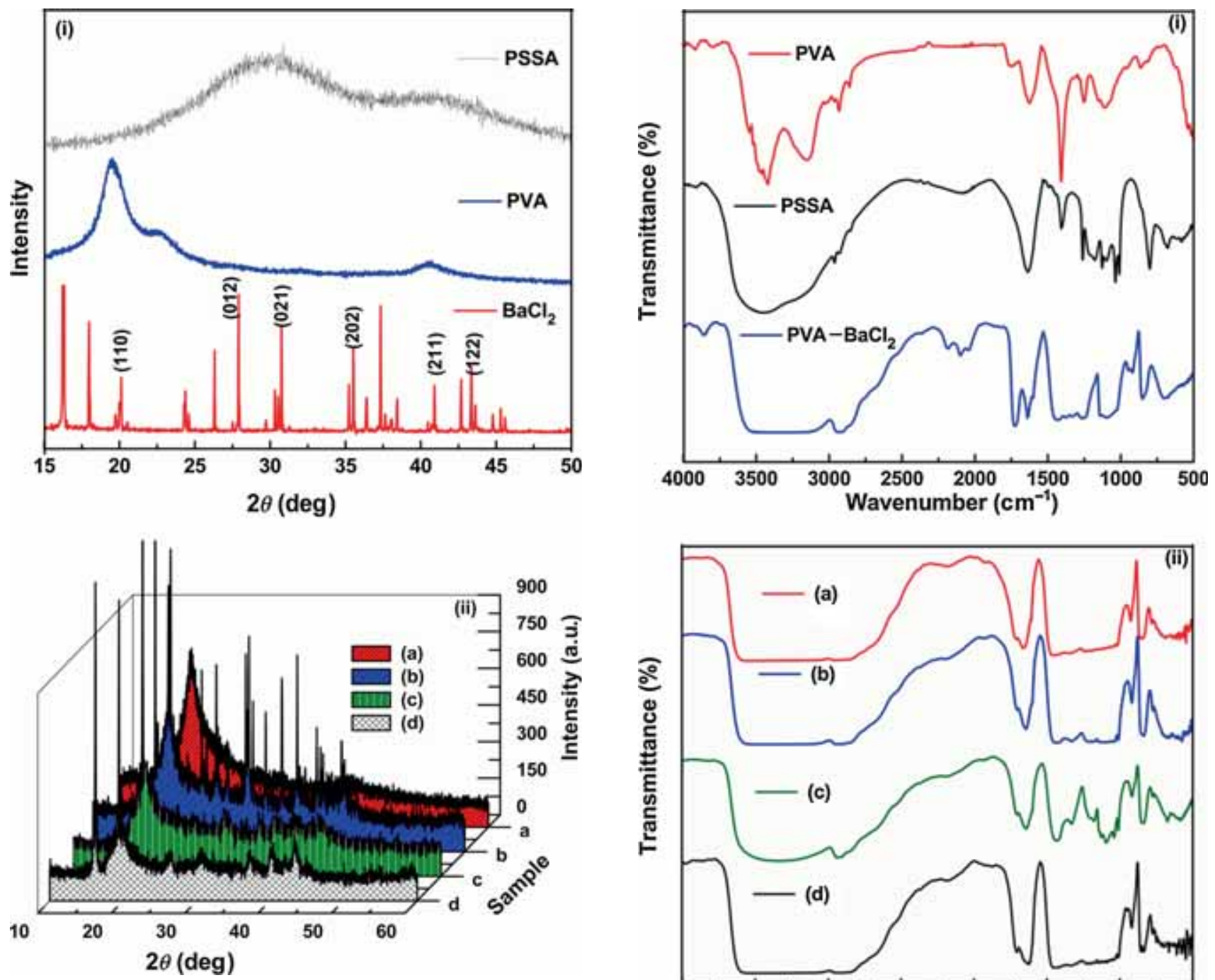

Figure 2. XRD spectra of (i) pure PSSA, PVA and $\mathrm{BaCl}_{2}$, and (ii) PSSA/PVA/ $\mathrm{BaCl}_{2}$ for different concentrations (a) 45:50:5, (b) 40:50:10, (c) 35:50:15 and (d) 30:50:20.

Table 1. Structural parameters of PSSA-PVA- $\mathrm{BaCl}_{2}$ polymer electrolyte from XRD analysis.

\begin{tabular}{lcrrr}
\hline Sample code & Sample loading $(\mathrm{wt} \%)$ & $2 \theta(\mathrm{deg})$ & $d(\AA)$ & $D(\mathrm{~nm})$ \\
\hline Pure PSSA & PSSA 100 & 30.01 & 3.30 & 0.68 \\
Pure PVA & PVA 100 & 19.38 & 5.07 & 5.01 \\
a & PSSA-PVA- $\mathrm{BaCl}_{2} 45: 50: 5$ & 19.42 & 5.06 & 3.25 \\
b & PSSA-PVA- $\mathrm{BaCl}_{2} 40: 50: 10$ & 19.54 & 5.03 & 10.45 \\
c & PSSA-PVA- $\mathrm{BaCl}_{2} 35: 50: 15$ & 19.70 & 5.00 & 4.46 \\
$\mathrm{~d}$ & PSSA-PVA- $\mathrm{BaCl}_{2} 30: 50: 20$ & 19.72 & 4.96 & 3.78 \\
\hline
\end{tabular}

On addition of $\mathrm{BaCl}_{2}$, the FTIR peak of pure PVA is shifted to $3115,2910,1249,1141,947$ and $850 \mathrm{~cm}^{-1}$ as shown in figure 3(i). This shift in wavenumber is due to cross-linkage of $\mathrm{BaCl}_{2}$ with host polymer. The FTIR band for pure PSSA as shown in figure 3(i) with the peak centred at $1200 \mathrm{~cm}^{-1}$

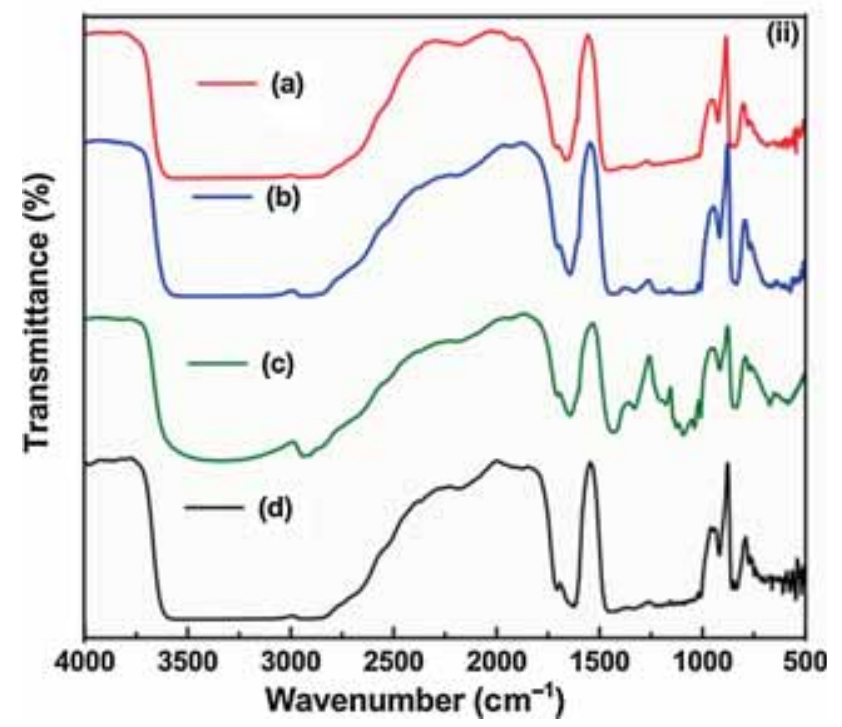

Figure 3. FTIR spectra of (i) pure PVA, PSSA and PVA/ $\mathrm{BaCl}_{2}:$ : 50:50 and (ii) PSSA/PVA/ $\mathrm{BaCl}_{2}$ for different concentrations (a) 45:50:5, (b) 40:50:10, (c) 35:50:15 and (d) 30:50:20 loading wt\%.

represents an asymmetric stretching vibration of the $\mathrm{O}=\mathrm{S}=\mathrm{O}$ unit. The peak at $1005 \mathrm{~cm}^{-1}$ results from the vibrations of the phenyl ring substituted with a sulphonic group. The broadening of this peak and overlapping with the phenyl ring with attached sulphonic anion peak located at $1125 \mathrm{~cm}^{-1}$ indicates the deprotonation of the sulphonic acid peak. The FTIR spectrum for 5, 10, 15 and $20 \mathrm{wt} \%$ loading of $\mathrm{BaCl}_{2}$ with PVA-PSSA host polymers is shown in figure 3(ii). The polymer electrolyte with $5 \mathrm{wt} \%$ loading of $\mathrm{BaCl}_{2}$ presents the FTIR peaks at $3197 \mathrm{~cm}^{-1}$ assigned for $-\mathrm{OH}$ vibration, $2954 \mathrm{~cm}^{-1}$ for $\mathrm{C}-\mathrm{H}$ stretching, $1406 \mathrm{~cm}^{-1}$ for $\mathrm{C}-\mathrm{H}$ deformation and at $1325 \mathrm{~cm}^{-1}$ for $\mathrm{C}-\mathrm{O}$ stretching as shown in figure 3(ii)-a. The peaks have been shifted to 3061, 2902, 1641 and $1408 \mathrm{~cm}^{-1}$ for $10 \mathrm{wt} \%$ loading of $\mathrm{BaCl}_{2} \cdot 2 \mathrm{H}_{2} \mathrm{O}$ in polymer electrolyte corresponding to $\mathrm{C}-\mathrm{H}$ stretching, $\mathrm{C}=\mathrm{O}$ stretching 
vibration, $-\mathrm{OH}$ vibration and $\mathrm{C}-\mathrm{H}$ deformation, respectively, as shown in figure 3(ii)-b. A drastic shift of FTIR peaks has been obtained for higher loading (wt $\%$ ) of $\mathrm{BaCl}_{2} \cdot 2 \mathrm{H}_{2} \mathrm{O}$ in the polymer electrolyte as shown in figure 3(ii)-c and d. The FTIR peak for $20 \mathrm{wt} \%$ loading of $\mathrm{BaCl}_{2} \cdot 2 \mathrm{H}_{2} \mathrm{O}$ obtained at $3099 \mathrm{~cm}^{-1}$ is assigned for $-\mathrm{OH}$ vibration, $2954 \mathrm{~cm}^{-1}$ for $\mathrm{C}-\mathrm{H}$ stretching, $1624 \mathrm{~cm}^{-1}$ for $-\mathrm{OH}$ bending (absorbed water) and $1408 \mathrm{~cm}^{-1}$ for $\mathrm{C}-\mathrm{H}$ deformation. This implies the aggregation of multiple ions when the loading (wt\%) of $\mathrm{BaCl}_{2}$ increases in the polymer electrolyte. These changes are attributed to the interaction of molecules of the salts with the host polymer system. This confirms the complex formation in PSSA-PVA$\mathrm{BaCl}_{2} \cdot 2 \mathrm{H}_{2} \mathrm{O}$.

\subsection{UV-visible spectra analysis}

The UV-visible study has been carried out to determine the optical band gap of polymer electrolyte. The study of optical absorption gives information about different analyses such as transition metal ions, highly conjugated organic compounds and biological macromolecules. Depending on the optical band gap value, materials are generally classified into insulators and semiconductors. The fundamental absorption, which corresponds to the transition from valence band to conduction band, can be used to determine the band gap of the material [20]. The optical absorbance of pure and $\mathrm{BaCl}_{2}$-doped polymer electrolytes in the range of $200-400 \mathrm{~nm}$ is shown in figure 4 . The optical absorbance results of pure polymer and pure inorganic compound $\left(\mathrm{BaCl}_{2}\right)$ are shown in figure 4 . The absorption band obtained in the region of $200 \mathrm{~nm}$ can be explained in terms of interaction or delocalization of the $\pi-\pi^{*}$ orbital. A shift in absorption band is obtained with different loadings (wt\%) of $\mathrm{BaCl}_{2}$ in polymer electrolytes as shown in figure $4 \mathrm{a}-\mathrm{d}$.

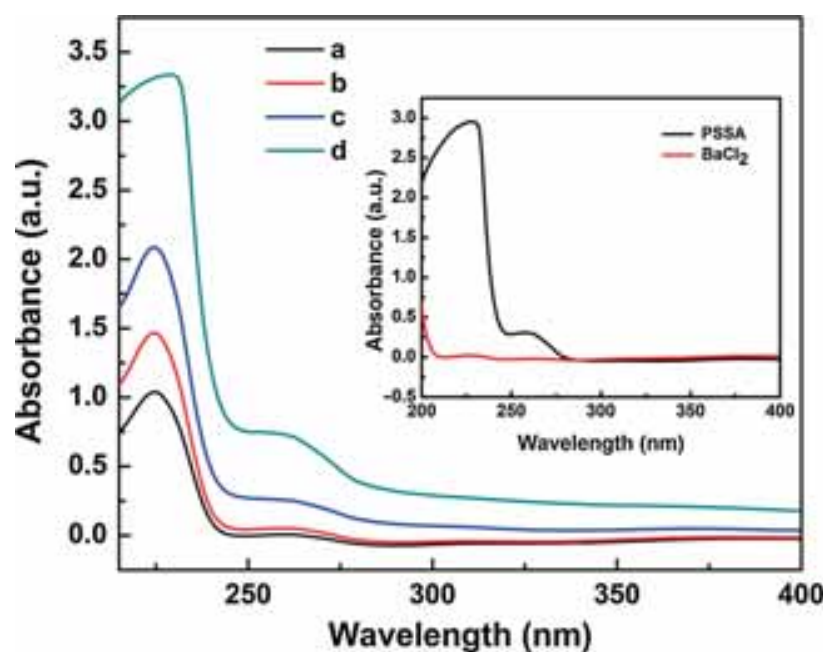

Figure 4. Optical absorbance spectra of PSSA/PVA/ $/ \mathrm{BaCl}_{2}$ for (a) 45:50:5, (b) 40:50:10, (c) 35:50:15 and (d) 30:50:20 loading wt $\%$. Inset represents the UV-vis spectra of pure PSSA and $\mathrm{BaCl}_{2}$.
The shift in wavelength of absorption peaks can be due to cross-linking between the polymer and inorganic compound. The absorption peaks are related to transition of electron. Therefore the shifting of absorption peaks toward lower or higher wavelength depends on the transition of electron $[21,22]$. To understand the absorption peak shift in UV-visible spectrum, the band gap energy $\left(E_{\mathrm{g}}\right)$ has been evaluated. The band gap value represents the movement of electron from valence band to conduction band and can also be correlated with phonons. The optical band gap $\left(E_{\mathrm{g}}\right)$ of the samples is evaluated using the following equation and Tauc plot method:

$$
(\alpha h v)^{n}=B\left(h v-E_{\mathrm{g}}\right),
$$

where $\alpha$ is the absorption coefficient, $h v$ is the photon energy and $n$ depends on the type of transition; $n$ may be equal to $1 / 2,2,3 / 2$ and 3 corresponding to the allowed direct, allowed indirect, forbidden direct and forbidden indirect transition, respectively. Figure 5(i, ii) presents the variation of $(\alpha h v)^{1 / 2}$ and $(\alpha h v)^{2}$ intercept on the $h v$ axis. The energy gap is obtained by fitting the linear part of the curve and finding the intersection of the straight line with the $h v$ axis. The estimated values of band gap energy $\left(E_{\mathrm{g}}\right)$ for $\mathrm{BaCl}_{2}$-doped polymer electrolyte are tabulated in table 2 .

The band gap value for pure PSSA and $\mathrm{BaCl}_{2}$ is 5 and $5.97 \mathrm{eV}$, respectively. However, the estimated direct band gap energy $\left(E_{\mathrm{g}}\right)$ value for 5-20 wt\% loading of $\mathrm{BaCl}_{2}$ in polymer electrolyte varies from 5.10 to $5.05 \mathrm{eV}$, respectively, as shown in table 2 . The band gap energy $\left(E_{\mathrm{g}}\right)$ decreases with loading (wt $\%$ ) of $\mathrm{BaCl}_{2}$. The estimated indirect band gap energy $\left(E_{\mathrm{g}}\right)$ value for 5-20 wt\% loading of $\mathrm{BaCl}_{2}$ in polymer electrolyte varies from 5.18 to $5.04 \mathrm{eV}$, respectively, as shown in table 2 . The decreased value of band gap energy $\left(E_{\mathrm{g}}\right)$ indicates that less energy is required to produce an electron-hole pair that does not separate into electron and hole. Hence in the produced electron-hole pair, electron and hole are electrically attracted to each other. The existence and variation of optical energy gap $E_{\mathrm{g}}$ may be explained by invoking the occurrence of local cross-linking in the amorphous phase of the polymer, in such a way as to increase the degree of ordering in these parts, which can also be helpful for the enhancement in ionic conductivity.

\subsection{Optical microscopy analysis}

The surface of polymer electrolyte films in the presence of $\mathrm{BaCl}_{2} \cdot 2 \mathrm{H}_{2} \mathrm{O}$ is further characterized by polarized optical microscopy. The microscopic examination of PSSA, PVA and $\mathrm{BaCl}_{2}$ in different ratios gives information about the homogeneity and phase transformation in the samples. Figure $6 \mathrm{a}-\mathrm{e}$ provides the microscopic images of $\mathrm{PVA}-\mathrm{BaCl}_{2}$ and PSSA-PVA- $\mathrm{BaCl}_{2}$ polymer composites. Homogeneity is observed in the presence of $\mathrm{BaCl}_{2}$ in pure PVA as shown in figure 6a. The plane dark surface represents the host polymer system, whereas the tiny dark bubble patterns are due 

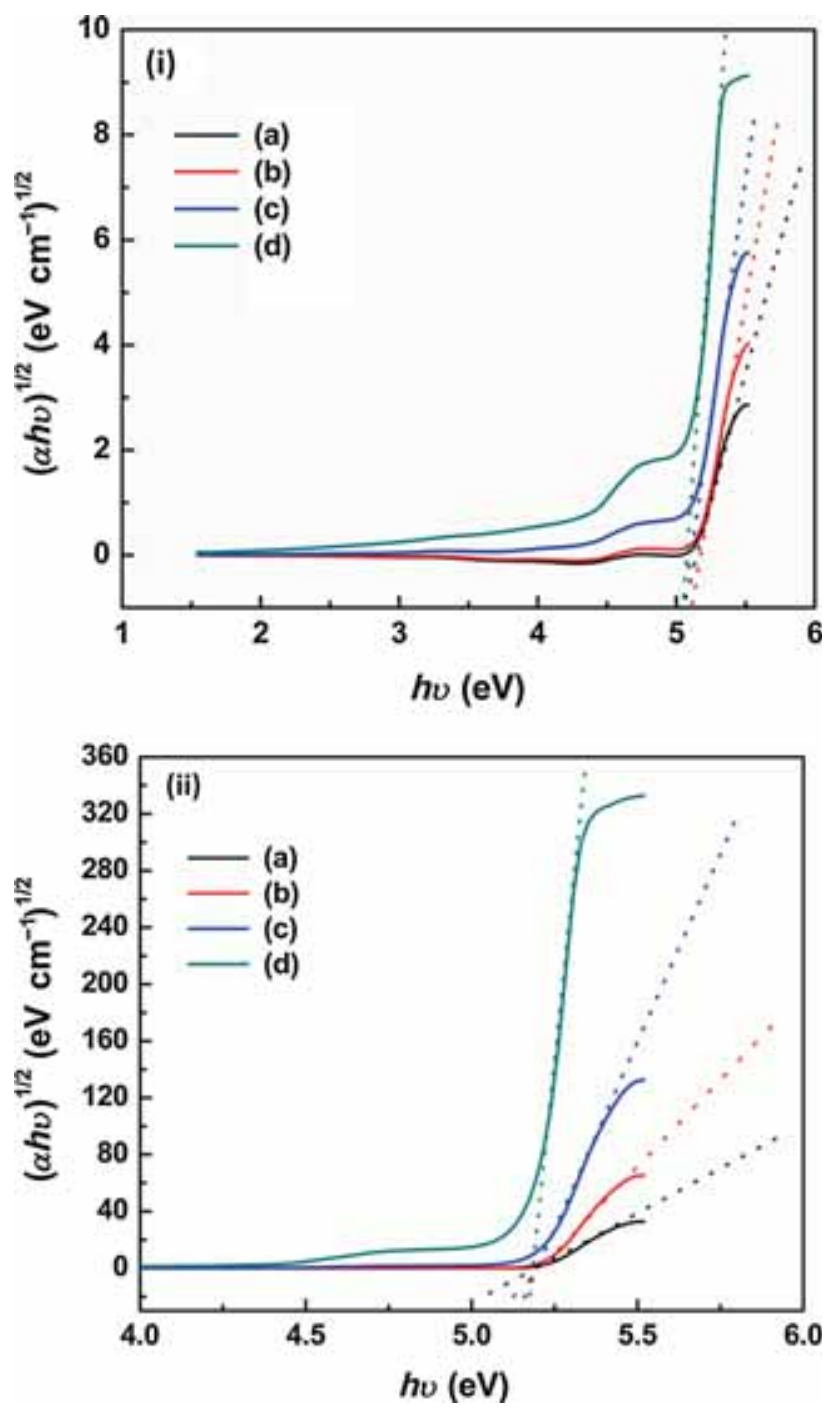

Figure 5. Plots for (i) direct optical band gap and (ii) indirect optical band gap for PSSA/PVA/ $\mathrm{BaCl}_{2}$ for (a) 45:50:5, (b) 40:50:10, (c) 35:50:15 and (d) 30:50:20 loading wt $\%$.

Table 2. Direct and indirect energy band gap values evaluated from UV-visible spectrum.

\begin{tabular}{lllc}
\hline \multicolumn{4}{c}{$E_{\mathrm{g}}(\mathrm{eV})$} \\
\cline { 2 - 4 } $\begin{array}{l}\text { Sample } \\
\text { code }\end{array}$ & Sample loading $(\mathrm{wt} \%)$ & $\begin{array}{l}\text { Direct } \\
\text { band gap }\end{array}$ & $\begin{array}{l}\text { Indirect } \\
\text { band gap }\end{array}$ \\
\hline a & PSSA-PVA-BaCl $245: 50: 5$ & 5.10 & 5.18 \\
b & PSSA-PVA- $\mathrm{BaCl}_{2} 40: 50: 10$ & 5.07 & 5.11 \\
c & PSSA-PVA-BaCl $235: 50: 15$ & 5.06 & 5.14 \\
d & PSSA-PVA- $\mathrm{BaCl}_{2} 30: 50: 20$ & 5.05 & 5.04 \\
\hline
\end{tabular}

to $\mathrm{BaCl}_{2}$. Figure $6 \mathrm{~b}$ shows that the PSSA-PVA- $\mathrm{BaCl}_{2}$ polymer electrolyte exhibits a plane non-volume-filling pattern, revealing a significant buildup of amorphous phase. This amorphous phase is obtained in the presence of low loading (wt $\%$ ) of $\mathrm{BaCl}_{2}$ in polymer electrolyte. This result can also be correlated with XRD results. However, for $10 \mathrm{wt} \%$ loading of $\mathrm{BaCl}_{2}$, a large amount of $\mathrm{BaCl}_{2}$ is distributed in the PVA-PSSA polymer system as shown in figure $6 \mathrm{c}$. The presence of large amount of $\mathrm{BaCl}_{2}$ leads to the filled up volume fraction of polymer system, which also reveals the semi-crystalline nature of polymer electrolyte. The strong cross-linkage among PSSA, PVA and $\mathrm{BaCl}_{2}$ is shown in figure $6 \mathrm{~d}$. The bright tiny bubble patterns occupying some particular position on the polymer surface represent the homogeneity and phase transformation. Furthermore, the polymer surface dominates in the presence of $\mathrm{BaCl}_{2}$ as shown in figure 6e. These strong cross-linkings of polymers restrict the movements of $\mathrm{BaCl}_{2}$ ion across the surface. Hence the present result obtained from polarized optical microscopy gives significant information regarding homogeneity of polymer electrolyte.

\subsection{DSC analysis}

The thermal properties are very important for polymer electrolyte to determine its melting point, glass transition temperature and rubbery phase for application. The DSC thermograms of pure PVA, PSSA polymers and its controlled composites are shown in figure 7(i, ii). The sharp endothermic peak observed at $190^{\circ} \mathrm{C}$ corresponds to crystalline melting temperature $\left(T_{\mathrm{m}}\right)$ of pure PVA as shown in figure 7(i). However, a broad peak has been observed for pure PSSA, which defines its amorphous nature, and the result can also be verified by XRD graph. The addition of $\mathrm{BaCl}_{2}$ to pure PVA polymer presents several endothermic peaks as shown in figure 7(i). The observed sharp peaks define the crystallinity of the system but reveal partial immiscibility. The DSC thermograms of PSSA-PVA polymer electrolyte for different loadings (wt\%) of $\mathrm{BaCl}_{2}$ are shown in figure 7(ii)$\mathrm{a}-\mathrm{c}$. There are several peaks obtained in DSC thermograms and we assume that this might be due to the presence of water. Hence the films were dried further and the DSC experiments repeated. Thus, we concluded that the peaks are not due to the presence of water. A shift in melting peak was observed with respect to change in loading (wt\%) of $\mathrm{BaCl}_{2}$, which also reveals the increase in crystallinity and immiscibility nature of polymer electrolyte. The melting enthalpy $\Delta H_{\mathrm{m}}$ was estimated experimentally at the heating point at which the substance changes its state from solid to liquid. The $\Delta H_{\mathrm{m}}$ of pure PVA and PSSA-PVA- $\mathrm{BaCl}_{2}$ polymer electrolyte is tabulated in table 3 . The relative percentage of crystallinity $\left(\chi_{c}, \%\right)$ is calculated on the basis of the following equation with the assumption that pure PVA is $100 \%$ crystalline:

$$
\chi_{\mathrm{c}}=\frac{\Delta H_{\mathrm{m}}}{\Delta H_{\mathrm{m}}^{\mathrm{o}}} \times 100 \%,
$$

where $\Delta H_{\mathrm{m}}^{\mathrm{o}}$ is the standard enthalpy of fusion of pure PVA and $\Delta H_{\mathrm{m}}$ is enthalpy of fusion of the composite polymer 


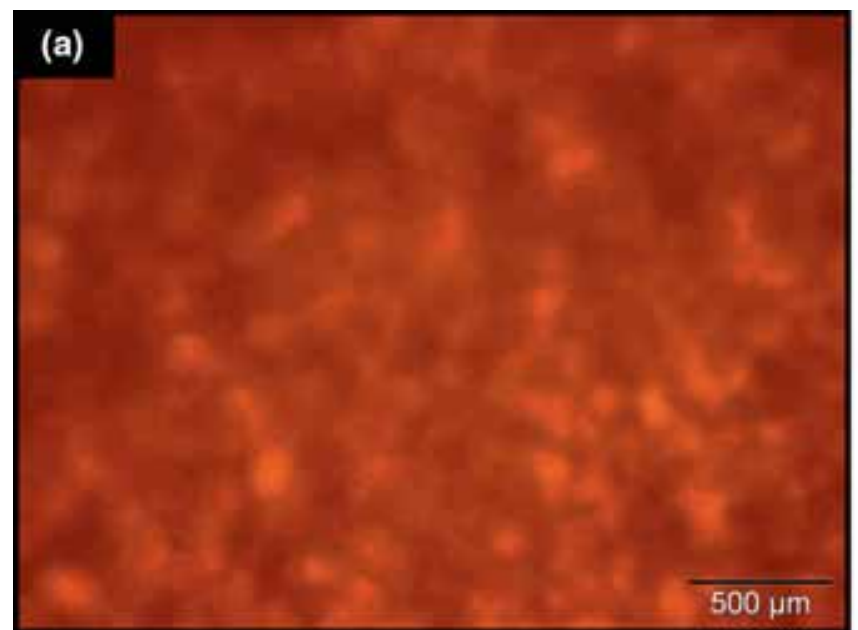

\section{(b)}
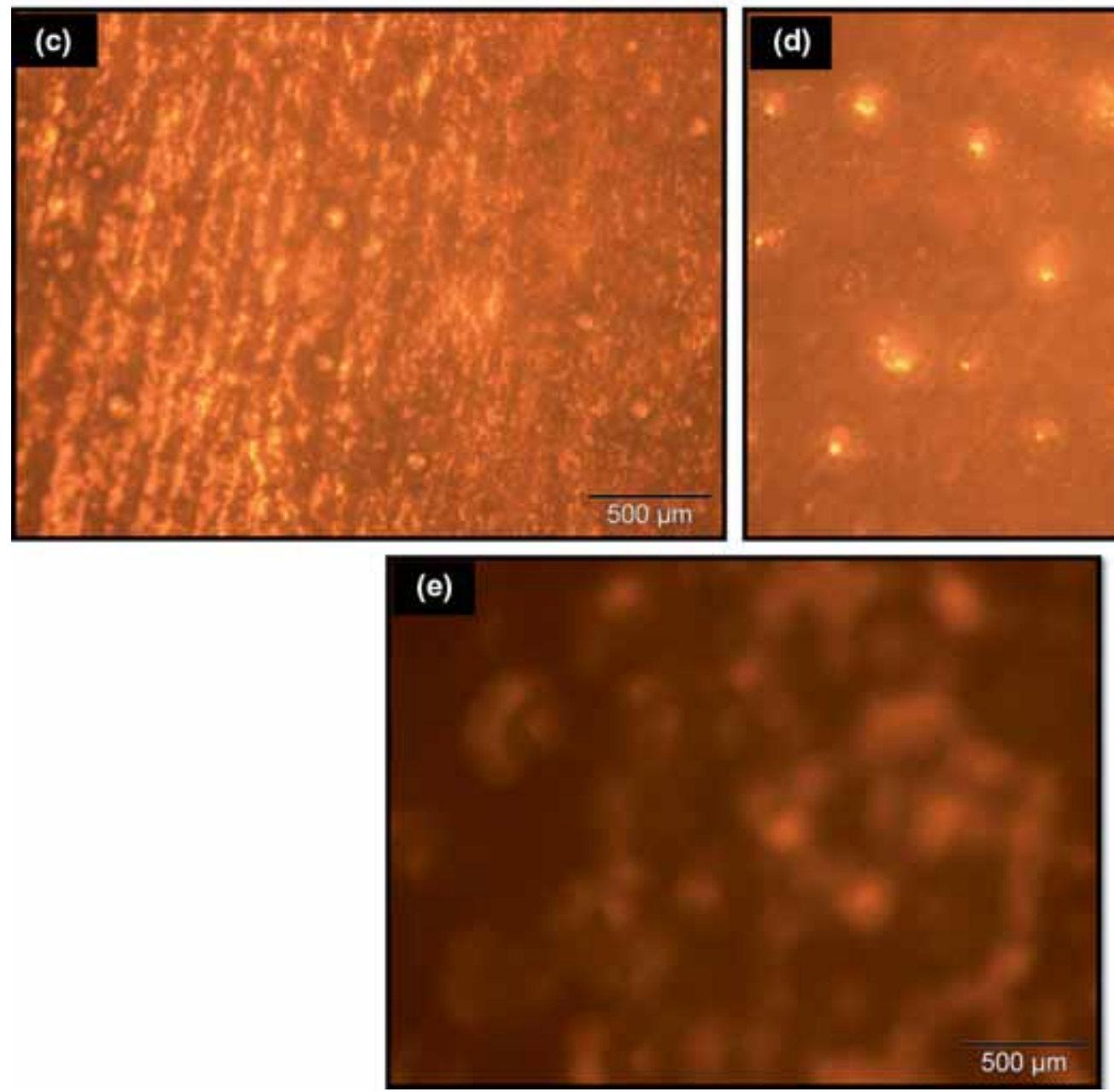

Figure 6. Optical micrographs of (a) $\mathrm{PVA} / \mathrm{BaCl}_{2}:: 50: 50$ and $\mathrm{PSSA} / \mathrm{PVA} / \mathrm{BaCl}_{2}$ for (b) 45:50:5, (c) 40:50:10, (d) 35:50:15 and (e) 30:50:20 loading wt $\%$.

electrolyte obtained directly from the DSC data. The $\chi_{\mathrm{c}}, \Delta H_{\mathrm{m}}$ and the crystalline melting temperature $\left(T_{\mathrm{m}}\right)$ of all polymer electrolytes are tabulated in table 3 . The crystallinity of polymer electrolyte increases with respect to loading (wt \%) of $\mathrm{BaCl}_{2}$. The highest crystallinity was observed for $15 \mathrm{wt} \%$ loading of $\mathrm{BaCl}_{2}$ in polymer electrolyte. The results are also confirmed from XRD data.

The polymeric chains are not very flexible in crystalline phase. The reduced segmental motion of polymer could be the reason for immiscibility of polymer electrolyte $[23,24]$. 

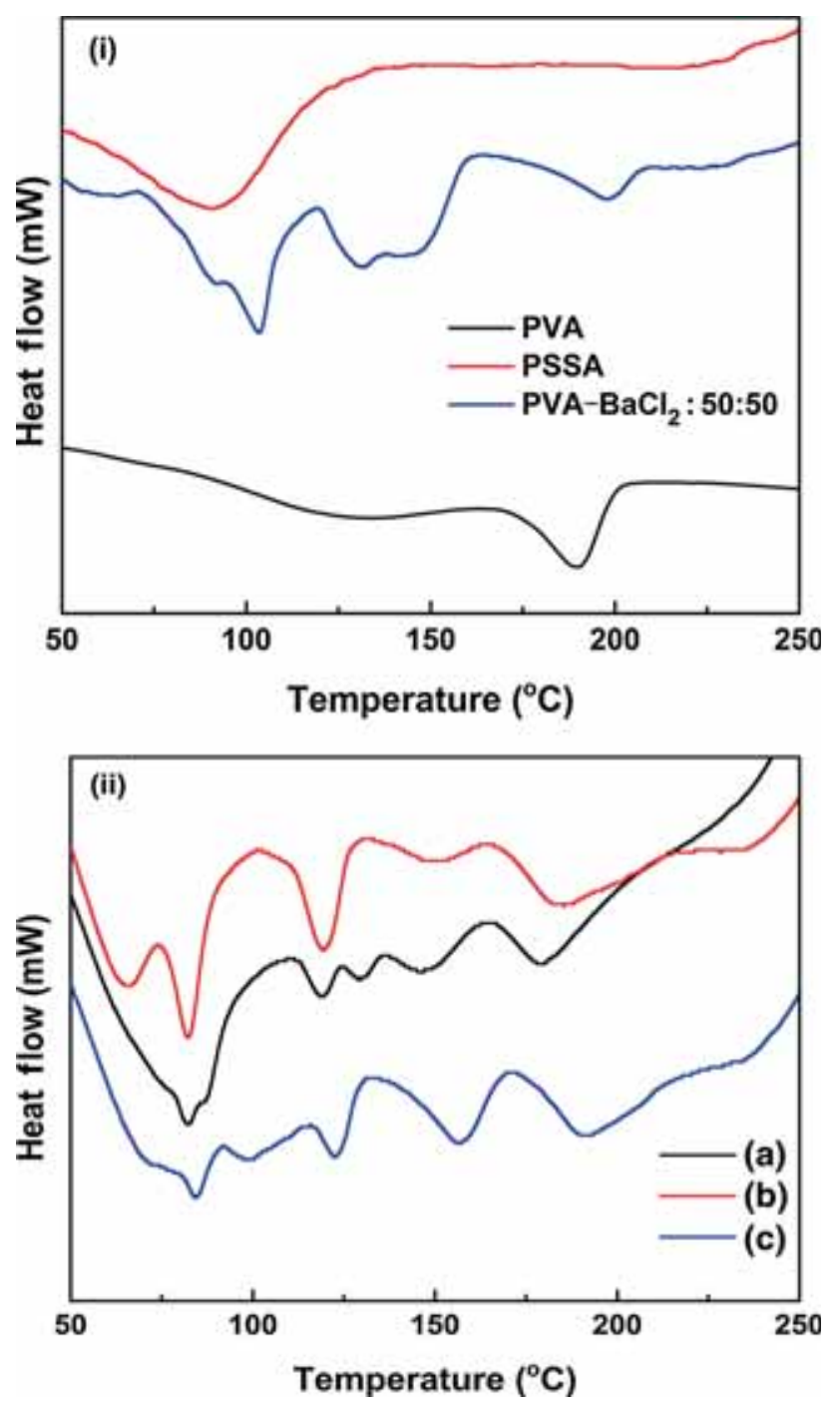

Figure 7. DSC thermograms of (i) pure PVA, PSSA and $\mathrm{PVA} / \mathrm{BaCl}_{2}:: 50: 50$ and (ii) $\mathrm{PSSA} / \mathrm{PVA} / \mathrm{BaCl}_{2}$ for different concentrations (a) 40:50:10, (b) 35:50:15 and (c) 30:50:20 loading wt\%.

Table 3. Thermal properties of (a) pure PVA, (b) pure PSSA, (c) PVA- $\mathrm{BaCl}_{2}$ for 50:50 loading (wt $\%$ ) and PSSA-PVA- $\mathrm{BaCl}_{2}$ for (d) 40:50:10, (e) 35:50:15 and (f) 30:50:20 loading (wt \%).

\begin{tabular}{lccc}
\hline Sample code & $T_{\mathrm{m}}\left({ }^{\circ} \mathrm{C}\right)$ & $\Delta H_{\mathrm{m}}\left(\mathrm{J} \mathrm{g}^{-1}\right)$ & $\chi_{\mathrm{c}}(\%)$ \\
\hline $\mathrm{a}$ & 190.47 & 54.5 & 100 \\
$\mathrm{~b}$ & 90.6 & 44.7 & 82 \\
$\mathrm{c}$ & 103 & 77.8 & 142 \\
$\mathrm{~d}$ & 119 & 2.35 & 4.3 \\
$\mathrm{e}$ & 119 & 12.26 & 22 \\
$\mathrm{f}$ & 122 & 4.52 & 8.3 \\
\hline
\end{tabular}

The resultant crystalline phase is expected to favour ion transport, which enhances the conductivity as well as diffusion coefficient of polymer electrolyte.

\subsection{Impedance spectroscopy analysis}

Impedance spectroscopy is a common technique for studying charge transport phenomenon in polymer electrolytes. The impedance method is widely used to investigate the electrical behaviour of materials over a wide range of temperature and frequency. In impedance spectroscopy the real and imaginary components of electrical parameters are separated. Figure $8 \mathrm{a}-\mathrm{c}$ presents the Nyquist $\left(Z^{\prime} v s . Z^{\prime \prime}\right)$ plot for different loadings ( $\mathrm{wt} \%$ ) of $\mathrm{BaCl}_{2}$ in polymer electrolyte at different temperatures $\left(30-150^{\circ} \mathrm{C}\right)$. A semicircular curve has been obtained by fitting the data in Z-view.

The impedance spectrum for $5 \mathrm{wt} \%$ loading of $\mathrm{BaCl}_{2}$ shown in figure $8 \mathrm{a}$ is characterized by the appearance of a single semicircular arc whose radius gradually decreases with increase in temperature. The intercept of each semicircular arc with $x$-axis gives the value of bulk resistance. A drastic change in impedance spectrum has been obtained at higher loading (10-20 wt $\%$ ) of $\mathrm{BaCl}_{2}$ in polymer electrolyte as shown in figure $8 \mathrm{~b}$ and $\mathrm{c}$. A decrease in semicircular pattern has been obtained with increased loading ( $\mathrm{wt} \%$ ) of $\mathrm{BaCl}_{2}$ in polymer electrolyte. This is due to the strong cross-linkage between salt and polymer ions at higher concentration. Hence it requires high temperature for the mobility of ions. Only a single semicircular arc at all temperatures demonstrates the grain effect other than the grain boundary and electrode effect [25]. The impedance response of PSSA-PVA- $\mathrm{BaCl}_{2}$ polymer electrolytes is due to the single conduction mechanism. This result leads to the conclusion that the current carriers are ions in the present polymer electrolytes. Hence the total conductivity is mainly due to ion conduction $[26,27]$.

\subsection{Ionic conductivity studies}

The ionic conduction mechanism is defined as the movement of ions from one site to another through the crystal lattice of a solid or aqueous solution. Ionic conductivity is a property to be considered in producing good polymer electrolytes. The ionic conductivity of the polymer electrolytes depends on the concentration of the salts and their mobility in the medium [28]. The resulting conductivity of polymer electrolyte is determined by ionic and segmental mobilities that assist the ion transport and retarding effect of ions [29]. In order to optimize the effect of $\mathrm{BaCl}_{2}$ in the polymer electrolyte on the basis of ionic conductivity, the loading (wt\%) of $\mathrm{BaCl}_{2}$ was increased from 5 to $20 \mathrm{wt} \%$. The change in ionic conductivity as a function of loading (wt $\%$ ) of $\mathrm{BaCl}_{2}$ at different temperatures is shown in figure 9. The highest room temperature conductivity $9.38 \times 10^{-6} \mathrm{~S} \mathrm{~cm}^{-1}$ was evaluated for $20 \mathrm{wt} \%$ loading of $\mathrm{BaCl}_{2}$ in polymer electrolyte as shown in figure 9 .

As the loading (wt\%) of inorganic compound increases, the number of carrier ions and $T_{\mathrm{g}}$ increase. The optimum conductivity is probably obtained due to the mobility of charge carriers and polymer segmental motion. The increased loading (wt\%) of $\mathrm{BaCl}_{2}$ disturbs the polymer chain. Thus, the 

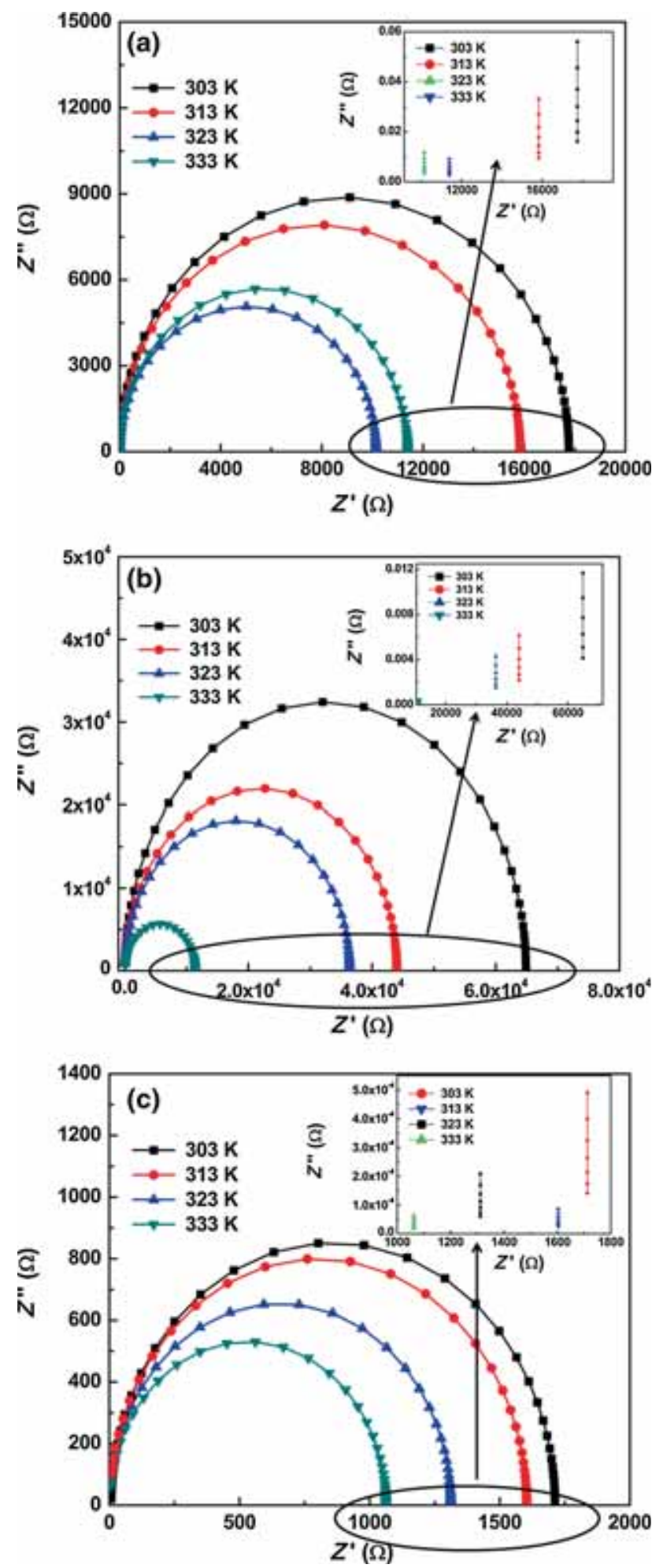

Figure 8. Complex impedance plane plots $\left(Z^{\prime \prime}\right.$ vs. $\left.Z^{\prime}\right)$ of PSSA/PVA/ $\mathrm{BaCl}_{2}$ for (a) 45:50:5, (b) 40:50:10 and (c) 35:50:15 loading $\mathrm{wt} \%$. Inset shows the $x$-intercept of the impedance plot.

main purpose of adding $\mathrm{BaCl}_{2}$ is to increase the free volume of polymer electrolytes, resulting in an increase in ionic conductivity.

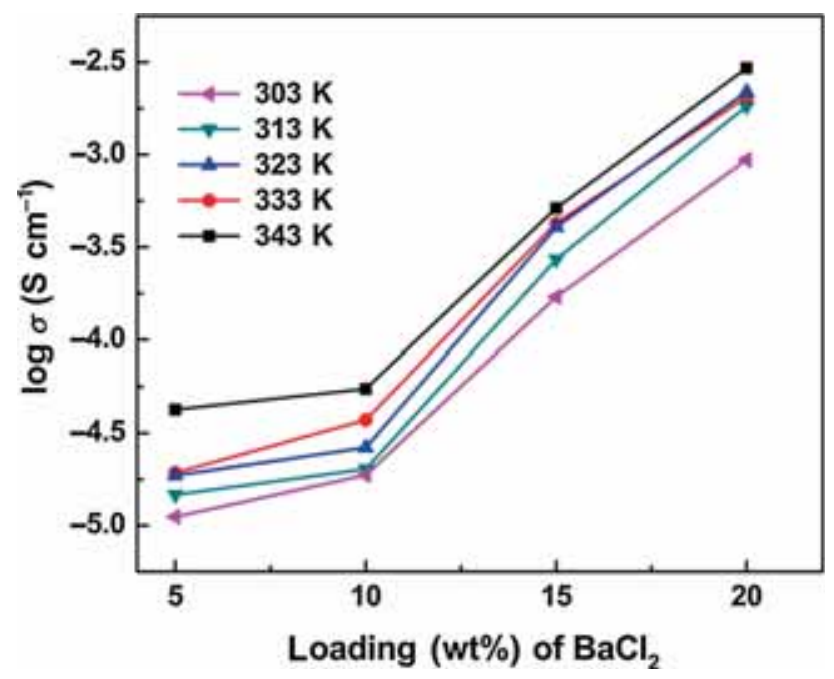

Figure 9. Salt concentration dependence ionic conductivity for $\mathrm{PSSA} / \mathrm{PVA} / \mathrm{BaCl}_{2}$ polymer electrolyte at different temperatures.

The ionic conduction may also occur as a function of temperature due to hopping process. The Arrhenius plot of pure and $\mathrm{BaCl}_{2}$-based polymer electrolyte is shown in figure 10 . The ionic conductivity values are calculated using the following equation:

$$
\sigma=\frac{l}{A R_{\mathrm{b}}}
$$

where $l$ and $A$ are the known thickness and area of the films, respectively, and $R_{\mathrm{b}}$ is the bulk resistance of the polymer electrolyte obtained from impedance plot. The temperature variation of conductivity of polymer electrolyte after addition of $\mathrm{BaCl}_{2}$ is shown in figure $10 \mathrm{a}-\mathrm{d}$. A linear trend is obtained after fitting the entire data using a linear fit of the Origin. The evaluated result clearly defines the change in conductivity after addition of $\mathrm{BaCl}_{2}$. Hence, $\mathrm{BaCl}_{2}$ plays a vital role in increasing the conductivity of present polymer electrolyte.

It is also observed that the ionic conductivity of polymer electrolyte increases as a function of temperature. This can also be defined as the free rationalized model $[30,31]$. At higher temperature, thermal movement of polymer chain segments and the dissociation of salt would be improved, which increase the ionic conductivity. Therefore, as the temperature increases the free volume increases in polymer electrolyte. The mobility of ions may also be described by evaluated activation energy as tabulated in table 4 . The evaluated activation energy for pure PSSA and PVA is 0.594 and $0.424 \mathrm{eV}$, respectively. The activation energy gradually decreases on addition of $\mathrm{BaCl}_{2}$; this is significant for high conductivity. It represents that the activation energy decreases at higher loading (wt $\%$ ) of $\mathrm{BaCl}_{2}$ in polymer electrolytes. However, at lower temperature the presence of $\mathrm{BaCl}_{2}$ leads to salt-polymer or cation-dipole interaction, which increases the cohesive energy of polymer 


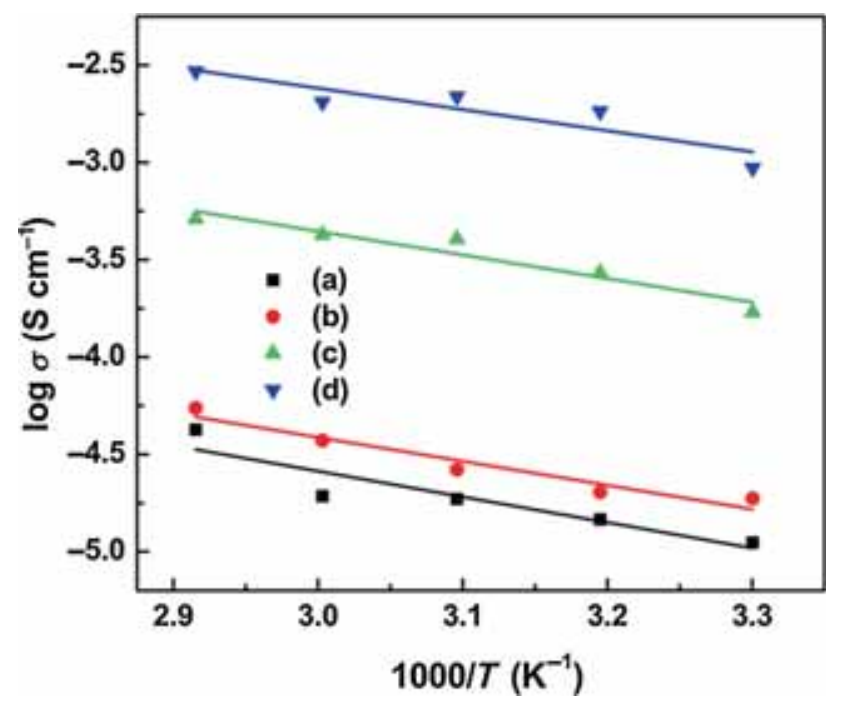

Figure 10. Temperature dependant ionic conductivity of PSSA/PVA/ $\mathrm{BaCl}_{2}$ for (a) 45:50:5, (b) 40:50:10, (c) 35:50:15 and (d) 30:50:20 loading wt $\%$.

Table 4. Activation energy from Arrhenius plots of pure PSSA, PVA and PSSA-PVA-BaCl 2 for (a) 45:50:5, (b) 40:50:10, (c) 35 : 50:15 and (d) 30:50:20 loading (wt\%) at different temperatures.

\begin{tabular}{lc}
\hline Sample code & Activation energy $(\mathrm{eV})$ \\
\hline Pure PSSA & 0.594 \\
Pure PVA & 0.424 \\
a & 0.26 \\
b & 0.24 \\
c & 0.23 \\
d & 0.22 \\
\hline
\end{tabular}

network. Hence, at lower temperature the free volume decreased and because of less ionic mobility the ionic conductivity decreased. As observed in FTIR studies, $\mathrm{Ba}^{2+}$ ion of $\mathrm{BaCl}_{2}$ interacts with -OH group of PVA and forms a complex in the form of intra/inter-molecular hydrogen bonding. This interaction and hence the complex formation causes structural variation within the polymer matrix. This structural variation increases with dopant concentration, which is reflected in the form of decrease in the energy band gap $E_{\mathrm{g}}$. This clarifies the role of $\mathrm{BaCl}_{2}$ in the present polymer electrolyte.

\subsection{Determination of diffusion coefficients and mobile charge concentration}

The diffusion coefficient describes the mobility of ions in polymer electrolyte system. In a salt-doped polymer system, both cations and anions can be mobile. However, the total number of charge carriers is difficult to quantify because a large fraction is bound in ion pairs or clusters. However the Trukhan model can be used to estimate the total charge carrier concentration [32]. The Trukhan model allows an

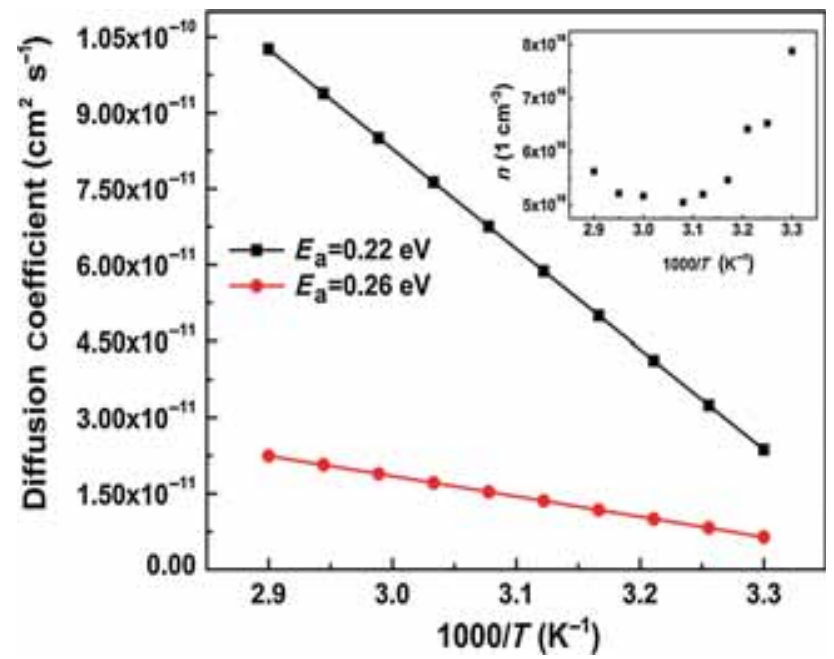

Figure 11. Arrhenius plot for the diffusion coefficient, computed according to Trukhan model. $E_{\mathrm{a}}=0.26 \mathrm{eV}$ for $5 \mathrm{wt} \%$ and $E_{\mathrm{a}}=0.22$ for $20 \mathrm{wt} \%$ loading of $\mathrm{BaCl}_{2}$ in PSSA/PVA polymer electrolyte. The inset graph represents the estimated ionic concentration as a function of temperature.

estimation of the diffusion coefficient and mobile ion concentration from the value of $\tan \delta$, where $\delta$ is a phase angle [33]. The diffusion coefficients $D^{+}$and $D^{-}$depend on the cations and anions of the salt dissolved in polymer system [34]. The theory of Trukhan describes dielectric dispersion caused by the electro-diffusion of ions. This is done in a confined dielectric medium, as an attempt to transcend the limitations of the Maxwell-Wagner-Sillars (MWS) theories of the impedance and complex permittivity of heterogeneous media. In the paper of Trukhan, binary 1:1 electrolytes are treated in two cases: (a) a homogeneous, conducting dielectric film between two non-conducting dielectric films and (b) a spherical, conducting phase embedded in an infinite amount of a non-conducting dielectric phase. The Trukhan model describes the case where the diffusion coefficients $D^{+}$and $D^{-}$of cations and anions are equal. The diffusion coefficient can be derived from the maximum of $\tan \delta$ spectra, the sample thickness $L$ and the frequency value at which $\tan \delta$ reaches the maximum. The diffusion coefficient can be evaluated from the formula [32]

$$
D=\frac{2 \pi f^{\max } L^{2}}{32(\tan \delta)_{\max }^{3}}
$$

Substituting the maximum $\tan \delta$ value in this equation, the diffusion coefficient was evaluated. Figure 11 presents the diffusion coefficient as a function of temperature for activation energy $E_{\mathrm{a}}=0.26$ and $0.22 \mathrm{eV}$, which is clearly of the Arrhenius type. The optimized response of diffusion coefficient as a function of temperature defines the semi-crystalline nature of polymer electrolyte. This could be due the effect of ions from $\mathrm{BaCl}_{2}$. The obtained semi-crystalline phase can be 
Table 5. Transference number of PSSA-PVA- $\mathrm{BaCl}_{2}$ polymer electrolytes for different concentrations.

\begin{tabular}{lll}
\hline & \multicolumn{2}{l}{ Transference number } \\
\cline { 2 - 3 } Polymer electrolyte (wt $\%)$ & $t_{\text {ion }}$ & $t_{\text {ele }}$ \\
\hline PSSA-PVA- $\mathrm{BaCl}_{2}(40: 50: 10)$ & 0.96 & 0.04 \\
PSSA-PVA-BaCl $(35: 50: 15)$ & 0.92 & 0.08 \\
PSSA-PVA-BaCl $2(30: 50: 20)$ & 0.88 & 0.12 \\
\hline
\end{tabular}

due to polymer hopping and local segmental motion of the host polymers [35]. Therefore the obtained activation energy for semi-crystalline phase is high. The ionic conductivity can also be correlated to the ion-ion interaction inside the polymer composite system. The mobility of ions demonstrates the behaviour of present polymer electrolyte. The total ion concentration is represented by $n$ and can be evaluated by the following equation:

$$
n=\frac{\sigma}{D} \frac{k T}{e^{2}}
$$

where $e$ is the elementary charge, $D$ is diffusion coefficient, $\sigma$ is ionic conductivity, $k$ is Boltzmann's constant and $T$ is absolute temperature.

The inset of figure 11 shows the estimated free ion concentration as a function of temperature. The evaluated ion concentration decreases up to $40^{\circ} \mathrm{C}$ and then again starts increasing. The temperature at which the ion concentration is fairly constant can be defined as fusion temperature $\left(40^{\circ} \mathrm{C}\right)$. The changing trend of ion concentration as a function of temperature could be due to the effect of dissolved ions trapped in polymer semi-crystalline matrix. The transference numbers of PSSA-PVA- $\mathrm{BaCl}_{2}$ polymer electrolyte corresponding to ionic $\left(t_{\text {ion }}\right)$ and electronic $\left(t_{\text {ele }}\right)$ transport have been evaluated using the Wagner polarization technique [36]. The transference numbers $\left(t_{\text {ion }}\right.$ and $\left.t_{\text {ele }}\right)$ are calculated using the relation

$$
\begin{aligned}
& t_{\text {ion }}=\frac{I_{\mathrm{i}}-I_{\mathrm{f}}}{I_{\mathrm{i}}}, \\
& t_{\text {ele }}=1-t_{\text {ion }},
\end{aligned}
$$

where $I_{\mathrm{i}}$ is initial current and $I_{\mathrm{f}}$ is the final residual current. The resulting transference number for different compositions of PSSA-PVA- $\mathrm{BaCl}_{2}$ polymer electrolyte is shown in table 5 . The transference number is measured to be $0.96-0.88$, which indicates that the conduction in electrolyte is predominantly ionic and only a negligible contribution comes from electrons. A very slight change in transference number upon ion irradiation confirms that the ion irradiation does not change the conduction mechanism [37]. The evaluated values of ion concentration and transference number for the present polymer electrolyte are approximately similar to those of other polymer electrolytes [38].

\section{Conclusions}

A polymer electrolyte consisting of PSSA, PVA and $\mathrm{BaCl}_{2} \cdot 2 \mathrm{H}_{2} \mathrm{O}$ was developed and characterized. The structural, thermal and electrical analysis revealed that loading of $\mathrm{BaCl}_{2}$ in the PSSA-PVA polymer system had a positive effect on ionic motion as well as phase structure of polymer. The XRD result describes the semi-crystalline nature of polymer electrolyte. A change in chemical composition was observed in FTIR spectroscopy. The optical band gap values evaluated from UV spectroscopy show an increasing trend with increasing loading (wt\%) of $\mathrm{BaCl}_{2}$ in polymer electrolyte. Results of optical band gap measurement from UV spectrum indicate the presence of $\pi-\pi^{*}$ transition by increase in $E_{\mathrm{g}}$ values as a function of $\mathrm{BaCl}_{2}$ loading in polymer system. DSC analyses highlighted the immiscibility and crystalline nature of polymer electrolyte. The DSC results were also confirmed by the XRD results. The ionic conductivity enhancement observed in PSSA-PVA- $\mathrm{BaCl}_{2}$ system evidently results from the effect of the compound. The ionic conductivity depends on salt concentration and increases with loading (wt\%) of $\mathrm{BaCl}_{2}$. The highest room temperature conductivity evaluated was $9.38 \times 10^{-6} \mathrm{~S} \mathrm{~cm}^{-1}$ for $20 \mathrm{wt} \%$ loading of $\mathrm{BaCl}_{2}$ in polymer electrolyte. The Arrhenius relationship, which shows hopping of ions in polymer composites, describes the temperature-dependent ionic conductivity of the polymer electrolyte. The diffusion coefficient parameter for barium chloride salt dissolved in polymer electrolyte, which describes the movement of cations and anions, is determined by loss tangent spectra. The transference number and enhanced conductivity imply that the charge transportation is due to ions. Therefore this polymer electrolyte can be further used for the development of electrochemical device applications.

\section{Acknowledgements}

We are highly grateful to the Naval Research Board, Defense Research and Development Organization, New Delhi, for providing electrical characterization facility under Project Number 259/Mat./11-12.

\section{References}

[1] Saikia D, Kumar A, Singh F and Avasthi D K 2006 J. Phys. D: Appl. Phys. 394208

[2] Wang G, Zhou X, Li M, Zhang J, Kang J, Lin Y et al 2004 Mater. Res. Bull. 392113

[3] Sun B, Mindemark J, Edstrom K and Brandell D 2014 Solid State Ion. 262738

[4] Ahm J H, Wang G X, Liu H K and Dou S X 2003 J. Power Sources 119422

[5] Sosa G H, Eckstein R, Tekoglu S, Becker T, Mathies F, Lemmer U et al 2013 Org. Electron. 142223 
[6] Seo J A, Koh J H, Roh D K and Kim J H 2009 Solid State Ion. 180998

[7] Lin C W, Huang Y F and Kannan M 2007 J. Power Sources 171 340

[8] Yang C C, Lin S J and Wu G M 2005 Mater. Chem. Phys. 92 251

[9] Prajapati G K and Gupta P N 2009 Nucl. Instrum. Methods Phys. Res. Sec. B 2673328

[10] Park J T, Koh J H, Roh D K, Shul Y G and Kim J H 2011 Int. J. Hydrogen Energy 361820

[11] Ayşe A, Kurtuluş G and Ayhan B 2012 J. Polym. Res. 1922

[12] Santhosh P, Gopalan A, Vasudevan T and Lee K P 2006 Mater. Res. Bull. 411023

[13] Vijayakumar G, Karthick S N, SathiyaPriya A R, Ramalingam S and Subramania A 2008 Solid State Electrochem. 121135

[14] Dissanayake M A K L, Bandara L R A K, Karaliyadda L H, Jayathilaka P A R D and Bokalawala R S P 2006 Solid State Ion. 177343

[15] Puguan J M C, Chinnappan A, Kostjuk S V and Kim H 2015 Mater. Res. Bull. 69104

[16] Hodge R M, Edward G H and Simon G P 1996 Polymer 37 1371

[17] Natrajan R, Subramanian S, Moni P, Shunmugavel K and Sanjeeviraja C 2013 Bull. Mater. Sci. 36333

[18] Hema M, Selvasekeranpandian S, Hirankumar G, Sakunthala A, Arunkumar D and Nithya H 2009 J. Phys. Chem. Solids 70 1098

[19] Bushkova O V, Popov S E, Yaroslavtseva T V, Zhukovsky V $\mathrm{M}$ and Nikiforov A E 2008 Solid State Ion. 1781817

[20] Ibrahim S, Ahmad R and Johan M R 2012 J. Lumin. 132147

[21] Al-Gaashani R, Radiman S, Tabet N and Daud R 2012 Mater. Sci. Eng. B 177462
[22] Ahmed F A H 2016 Bull. Mater. Sci. 39209

[23] Nasir N H A, Chan C H, Kammer H W, Sim L H and Yahya M Z A 2010 Macromol. Symp. 29046

[24] Vargas M A, Vargas R A and Mellander B E 2000 Electrochem. Acta 451399

[25] Martos A M, Sanchez J Y, Varez A and Levenfeld B 2015 Polym. Test. 45185

[26] Singh P K, Kim K W, Nagarale R K and Rhee H W 2009 J. Phys. D: Appl. Phys. 42125101

[27] Huang X, Xianguo M, Gao J, Tan B, Yang K, Wang G et al 2012 Solid State Ion. 2157

[28] Kuan W F, Remy R, Mackay M E and Thomas H 2015 RSC Adv. 512597

[29] Fahmi E M, Ahmad A, Nazeri N N M, Hamzah H, Razali H and Rahman M Y A 2012 Int. J. Electrochem. Sci. 75798

[30] Rajendran S, Babu R S and Sivakumar P 2007 J. Power Sources 170460

[31] Chandra A, Agrawal R C and Mahipal Y K 2009 J. Phys. D: Appl. Phys. 42135107

[32] Soresen T S and Compan V 1995 J. Chem. Soc. Faraday Trans. 914235

[33] Munar A, Andrio A, Iserte R and Compan V 2011 J. Non-Cryst. Solids 3573064

[34] Edman L, Ferry A and Oradd G 2002 Phys. Rev. E 65 042803

[35] Karan N K, Pradhan D K, Thomas R, Natesan B and Katiyar R S 2008 Solid State Ion. 179689

[36] Wagner J B and Wagner C J 1957 J. Chem. Phys. 261597

[37] Reddy C V S, Sharma A K and Narasimha Rao V V R 2003 J. Power Sources 114338

[38] Klein R J, Zhang S, Dou S, Jones B H, Colby R H and Runt J 2006 J. Chem. Phys. 124144903 